\title{
Re: Assessment of Viable Tumour Tissue Attached to Needle Applicators after Local Ablation of Liver Tumours
}

\author{
C.T. Sofocleous N.Petre K. Manova-Todorova L.Petrovic M. Gonen \\ Memorial Sloan-Kettering Cancer Center, New York, N.Y., USA
}

Dear Sir,

We have read with great interest the paper by Snoeren et al., entitled 'Assessment of viable tumour tissue attached to needle applicators after local ablation of liver tumours' [1]. The authors commented that the finding in our earlier publication [2] where intact tumor cells were detected by simple HE examinations on tissue extracted on the RITA Starburst XL electrode after ablation of liver malignancies is remarkable. This finding was not in accordance with their findings where viable tumor was only found on the Leveen Radiotherapeutics device [1]. In order to improve the limitations of morphologic stains alone in our initial study [2], we performed evaluation of fixed specimens with proliferation marker Ki67 [3, 4] and apoptosis marker caspase 3 [5]. This study [6] demonstrated that tumor cells positive for Ki67 carry a risk of approximately 6 times for local tumor progression (LTP) when compared to those that are Ki67negative (hazard ratio 5.9, 95\% CI 2.4$14.5, \mathrm{p}<0.001)$. Furthermore, for the subset of tumors under $3 \mathrm{~cm}$ in largest diameter, this risk is over 10 times for the Ki67-positive tumor cells when compared to those that test negative (hazard ratio $10.1,95 \%$ CI 1.7-57.5, $\mathrm{p}=0.009$ ). In this study, we collected specimens after RF ablation with the Leveen $(n=54)$ and the
RITA XL ( $n=14)$ electrodes [6]. 13/68 (19\%) specimens were positive for Ki67, $12 / 54(22.2 \%)$ from the Leveen and $1 / 14$ (7\%) from the RITA electrode. This difference was not statistically significant $(p=0.27)$. Should this trend remain the same, a statistically significant difference could be established if the population was 250 .

We have certain questions regarding the methodology of Snoeren et al. [1]:

(1) Is it possible that any cells reacting to the G6PD were normal viable hepatocytes and not tumor?

(2) Macroscopic tissue adherent on RITA electrodes was seen in $87.5 \%$ cases. Did all these specimens contain completely destructed, non-identifiable cells? Were there any nests of identifiable tumor cells with or without changes of thermal injury?

(3) It appears that tissue was found in $7 / 8$ cases $(87.5 \%)$ treated with the RITA electrode. Is it possible that the differences in the incidence of viable tumor cells between electrodes would be different with the addition of more cases?

(4) The inability to resect with a clear, tumor-free margin, and multifocal and extrahepatic disease were indications for ablation. Was the ratio of patients with these factors similar between the groups that were treated with the Leveen when compared to the other electrodes?

(5) Are the authors planning to report on the incidence of LTP and track seeding in their population in order to identify any correlation with their tissue findings?

Several publications evaluating tissue changes after ablation in animal tumor models [7, 8] and human hepatic malignant tumors $[9,10]$ have demonstrated that the presence of tumor cells in the HE stain corresponds to viable tumor. In our publication, identifiable tumor cells were examined with proliferation marker Ki67, confirming the proliferation and viability of those cells [6]. Tumor cells were more commonly identified after the use of the Leveen when compared to the Starburst Xl electrode; however, this difference was not significant [6]. The presence of Ki67-positive tumor cells on tissue extracted on the electrode was identified as an independent prognostic risk factor of LTP as mentioned above [6]. This marker as well as caspase 3 can be evaluated in fixed specimens allowing evaluation of the same tumor cells identified with the HE stains.

Snoeren et al. [1] attributed their findings to the inability to perform track ablation with the Leveen electrode after treat-

\section{KARGER}

(C) 2009 S. Karger AG, Basel

Fax +41613061234 E-Mail karger@karger.ch www.karger.com www.karger.com/dsu
Constantinos T. Sofocleous, MD, PhD, FSIR

Memorial Sloan-Kettering Cancer Cente

1275 York Ave, Suite H118

New York, NY 10065 (USA)

Tel. +1 212639 3379, Fax +1 212717 3325, E-Mail sofoclec@mskcc.org 
ment. Although this is an important point and may be related to the presence of viable tumor in their series, no viable tumor should remain on the electrode if ablation of the tumor with creation of an adequate clear margin was successful. It is therefore important to select patients for ablation when tumor treatment with a clear margin can indeed be reasonably achieved. In any other case, ablation should not be offered with a curative intent.

The performance of tissue examinations in the ablated tumors is important to confirm coagulation necrosis or detect residual viable tumor, able to proliferate. This may allow identification of patients at risk of LTP and additional treatment that may improve outcomes.

\section{Disclosure Statement}

C.T.S., L.P. and M.G. received research support from the National Institute of Health (R21-CA131763) for research related to this publication.

\section{References}

1 Snoeren N, Jansen MC, Rijken AM, van Hillesgersberg R, Slooter G, Klaase J, van der Tol PM, van der Linden E, Ten Kate FJW, van Gulik TM: Assessment of viable tumour tissue attached to needle applicators after local ablation of liver tumours. Dig Surg 2009;26:56-62.

2 Sofocleous CT, Klein KM, Hubbi B, Brown KT, Weiss SH, Kannarkat G, Hinrichs CR, Contractor D, Bahramipour P, Barone A, Baker SR: Histopathologic evaluation of tissue extracted on the radiofrequency probe after ablation of liver tumors: preliminary findings. AJR Am J Roentgenol 2004;183: 209-213.

3 Scalzo DA, Kallakury BV, Gaddipati RV, Sheehan CE, Keys HM, et al: Cell proliferation rate by MIB-1 immunohistochemistry predicts postradiation recurrence in prostatic adenocarcinomas. Am J Clin Pathol 1998; 109:163.

4 Scholzen T, Gerdes J: The Ki-67 protein: from the known and the unknown. J Cell Physiol 2000;182:311-322.

5 Budihardjo I, Oliver H, Lutter M, Luo X, Wang X: Biochemical pathways of caspase activation during apoptosis. Annu Rev Cell Dev Biol 1999;15:269-290.
6 Sofocleous CT NR, Petrovic L, Klimstra D, Gonen M, Brown KT, Brody LA, Covey AM, Thornton R, Fong Y, Solomon SB, Schwartz L, DeMatteo R, Getrajdman GI: Histopathologic and immunohistochemical features of tissue adherent to multitined electrodes after $\mathrm{RF}$ ablation of liver malignancies can help predict local progression: initial results. Radiology 2008;249:364-374.

7 Raman SS, Lu DS, Vodopich DJ, Sayre J, Lassman C: Creation of radiofrequency lesions in a porcine model: correlation with sonography, CT, and histopathology. AJR Am J Roentgenol 2000;175:1253-1258.

8 Lee JD, Lee JM, Kim SW, Kim CS, Mun WS: MR imaging-histopathologic correlation of radiofrequency thermal ablation lesion in a rabbit liver model: observation during acute and chronic stages. Korean J Radiol 2001;2: 151-158.

9 Morimoto M, Sugimori K, Shirato K, et al: Treatment of hepatocellular carcinoma with radiofrequency ablation: radiologic-histologic correlation during follow-up periods. Hepatology 2002;35:1467-1475.

10 Scudamore CH, Lee SI, Patterson EJ, et al: Radiofrequency ablation followed by resection of malignant liver tumors. Am J Surg 1999;177:411-417.

\title{
Reply
}

\author{
N. Snoeren ${ }^{a}$ M.C. Jansen ${ }^{a}$ F.J.W. ten Kate ${ }^{b} \quad$ T.M. van Gulik ${ }^{a}$
}

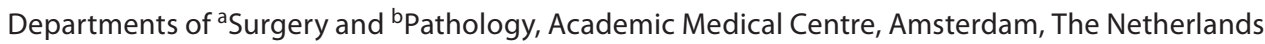

Dear Sir,

Sofocleous et al. suggested that cells staining positive for G6PD as described in our article [1] possibly represented normal viable hepatocytes and not tumour cells. Although this cannot be excluded, we have scored the G6PD-positive cells according to the nucleus/cytoplasm (N/C) ratio, which is usually higher in malignant cells $[2,3]$. The N/C ratios were comparable with the ratios found in the HE stains of cytospins of the same application. Ideally, a tumour-specific counterstain should be used to be absolutely sure.

Macroscopic tissue was present in $87.5 \%$ of cases after treatment with the RITA electrode. As we mentioned in our article, there were, however, no morphologically intact tumour cells present. Tissue attached to the needle applicator in 2 of 7 applications using the RITA electrode demonstrated microscopically identifiable cells. In one instance, these cells appeared to be intact liver cells. In the other application with recognisable cells, the cells proved to be tumour cells, with clear signs of thermal injury. The other 5 specimen contained completely destructed, nonidentifiable cells.

We agree with Sofocleous et al. that the addition of more cases could have made a difference in the incidence of viable cells found between the electrodes, especially since 24 applications were performed with the Radiotherapeutics (RTx) electrode and only 8 with the RITA electrode. This clearly was a limitation of our observational study in which we included all consecutive patients without predetermining the choice of ablation system used by the surgeon. We have to await future results of a more elaborate series to see if viable cells truly do appear more often after the RTx applicators compared to other needles. The cause for irresectability and indications for surgery were equally distributed over the ablation systems used. We are planning to report a follow-up study focusing on local tumour progression in our case material and, in this connection, read with great interest the paper of Sofocleous et al. [4]. We agree that caspase 3 and Ki67 are useful prognostic markers as also shown by Sofocleous et al. Immunohistochemical staining characteristics, however, may be preserved even in heat-fixed tissue [5]. For this reason we used G6PD staining to measure enzyme activity. We indeed attributed the finding of intact tumour cells on the applicators to the lack of performing track ablation. 